\title{
CLINICAL SYMPTOMS AND SEX STEROID MEASUREMENTS IN DOMESTIC FERRETS (MUSTELA PUTORIUS FURO) WITH HYPERADRENOCORTICISM
}

\author{
Silva Grīnblate, Aija Ilgaža \\ Latvia University of Agriculture \\ silva.grinblate@gmail.com.
}

\begin{abstract}
Hyperadrenocorticism (excessive adrenal production of sex steroids related to adrenocortical adenomas and carcinomas) is a common disease in neutered male and female pet ferrets (Mustela putorius furo) and causes significant morbidity. Incidence of ferret adrenal disease in Latvia is high because the majority of them are gonadectomized. The most common clinical symptoms include symmetrical alopecia and recurrence of sexual behavior. Sex steroids used to diagnose disease are estradiol, androstenedione and $17 \alpha-\mathrm{OH}$ progesterone. It is mentioned that androstenedione is the most sensitive during development of the disease. The aim of this study was to sum up, evaluate and compare clinical findings and blood hormone measurements in ferrets diagnosed with hyperadrenocorticism. Forty two ferrets $(\mathrm{n}=20$ female, $\mathrm{n}=22$ male) with various clinical symptoms related to hyperadrenocorticism were included in this research. Clinical examination based on clinical symptom protocol was performed and blood samples were taken in all cases. There is a high correlation between the age of neutering and onset of clinical signs in female ferrets. In both sexes, there is no correlation between clinical signs and levels of sex steroids. In male and female group, symmetrical alopecia, pruritus, scaling and fragility of skin and lethargy are the most common findings. During this research, a ranking system (from 1 to 4 ) for the severity of alopecia was developed. All ferrets had one or two elevated sex steroid levels. In our research, androstenedione was elevated in 25 cases out of 42 . Clinical signs and sex steroid measurements are important in diagnosing hyperadrenocorticism in ferrets.
\end{abstract}

Key words: Adrenal Disease, Alopecia, Lethargy, Pruritus, Sex steroids, Androstenedione.

\section{Introduction}

Adrenocortical disease has been recognized in many countries all over the world. It is seen in middleaged to older ferrets (Carpenter \& Quesenberry, 2012). Adrenocortical neoplasms are common in certain gonadectomized animals, including ferrets. These tumors may produce ectopic sex steroids that cause significant morbidity (Bielinska et al., 2006; Bielinska et al., 2009; Schillebeeck et al., 2015; Beuschlein, Galac, \& Wilson, 2012). Chronic elevation in circulating luteinizing hormone (LH) that follows gonadectomy is a reason for neoplastic transformation in the adrenal glands (de Jong et al., 2014). Furthermore, this transformation indicates abnormal hormonal levels causing the appearance of various clinical symptoms. In adult ferrets, LH receptors have been found not only in gonadal organ testicles and ovaries, but also in adrenal gland cortical part, which means that adrenal glands are taking part in the heat cycle regulation (Schoemeker et al., 2002). Adrenal weight is higher in animals in late proestrus or estrus than in animals in anestrus or early proestrus (Fox, 1988).

The most obvious symptoms of hyperadrenocorticism in ferrets are symmetrical alopecia, vulvar swelling in neutered jills and mating aggression in neutered males (Fox, 1988; Rosenthal \& Peterson, 2000). Alopecia is the most common clinical manifestation of adrenocortical disease and develops in both male and female ferrets. Alopecia is usually symmetrical, beginning on the rump, the tail, or the flanks with progression to the lateral trunk, dorsum, and ventrum. Hair epilates easily. Pruritusmay also be present, most frequently observed on the dorsum between the shoulder blades. Skin erosions can occur due to pruritus and fragility of skin (Hnilica, 2010; Keeble \& Meredith, 2009). More than $70 \%$ of female ferrets with adrenal gland disease have an enlarged vulva (Rosenthal et al., 1993). It is also proven that there is no sex predilection (Schoemeker et al., 2000). Perivulvar region may be hyperemic and covered with erosions (Hnilica, 2010). Mammary gland enlargement in female ferrets is also seen (Keeble \& Meredith, 2009). Partial or complete urinary blockage in male ferrets is occasionally associated with adrenocortical disease. Periurethral cysts develop in the region of the prostate (originating from hormone responsive cells) and cause urethral narrowing (Coleman, Chavez, \& Williams, 1998). Polyuria and polydipsia arealso reported in ferrets with hyperadrenocorticism, but it is not clear if the adrenal hormones are responsible for these symptoms. Enlarged abdomen may be seen in ferrets with adrenal disease as well (Fox, 1988; Banks et al., 2010).

At the beginning, clinical signs tend to appear in the breeding season but eventually they become persistent. Median time interval between neutering and diagnosis of hyperadrenocorticism is 3.5 years. A significant linear correlation between the age at neutering and age at time of diagnosis is detected. It is concluded that age at neutering may be associated with age at development of hyperadrenocorticism in ferrets (Schoemaker et al., 2000; Bielinska et al., 2006). 
Diagnosing is also based on increased plasma concentrations of androstenedione, $17 \alpha-\mathrm{OH}$ progesterone, dehydroepiandrosterone sulfate, and/or estradiol (Rosenthal \& Petherson, 1996). Reference ranges have been set by Clinical Endocrinology Laboratory, College of Veterinary Medicine, University of Tennessee, Knoxville: Androstenedione (nmol L-1) 0.1-15, Estradiol (pmol L-1) 30-108, 17 $\alpha$ $\mathrm{OH}$ progesterone (nmol L-1) 0.1-0.8. If one or more of these results are raised in a neutered ferret, this confirms hyperadrenocorticism. Androstenedione is the most sensitive of the above hormones (Meredith $\&$ Redrobe, 2002). Cortisol should be in normal range (Mitchell \& Tully, 2009).

In the Baltic States, there are no research papers about this condition in domestic ferrets. There is no ranking system for severity of alopecia, when ferrets are brought in for clinical examination. Also, here is no research describing if there is any correlation between clinical symptoms and sex steroid levels.

The aim of this study was to sum up, evaluate and compare clinical findings and blood hormone measurements in ferrets diagnosed with hyperadrenocorticism.

\section{Materials and Methods}

The research was carried out in three veterinary clinics in Latvia during the period from March 2013 till February 2016. Twenty two castrated male ferrets and twenty neutered female ferrets were included in this research at age of 36 to 66 months. All ferrets were under the owners' supervision and all of them had various clinical signs related to adrenal disease. All ferrets were held indoors and had feed and water ad libidum. They all were kept under the owners' supervision. Ferrets were randomly numbered from 1 to 42 for the owner data safety and privacy. Legal and ethical requirements had been met. Ferret owners were informed about their animals being included in the research under terms of privacy.

All ferrets were clinically examined. Animals were assessed by one examination protocol which included basic information (age, age of neutering/castration and gender) and questions about clinical symptoms observed in each animal.

During research, the ranking system for description of alopecia was developed. Severity of alopecia was ranked from 1 to 4 , where 1 - mild seasonal shedding on tail and dorsum, 2 - seasonal symmetrical alopecia on dorsum, ventrum and tail, 3 - persistent symmetrical alopecia on dorsum, ventrum, chest and tail, 4 - animal has lost all fur, except on head and paws. Blood samples were collected from each animal, sent to the Central laboratory (Riga, Šarlotes street 1B) and levels of estradiol, androstenedione and $17 \alpha-\mathrm{OH}$ progesterone were detected. Blood sampling was performed once in each animal, during the first clinical examination. Statistical analyses were carried out using MS Excel.

\section{Results and Discussion}

Mean age of neutering of ferrets included in this research is 11.3 months (SD 3.7). There is no significance between gender - male ferrets are castrated at 12 months of age (min. 8 months, max. 18 months) and female ferrets are neutered at 10.6 months of age (min. 7 months, max. 18 months) $\mathrm{p}<$ 0.05 .

The age at which the first clinical signs appear vary between 24 and 66 months and it depends on the age of neutering. Mean age at which the clinical symptoms appear is 43.2 months (SD 8.0). Mean age at which the first clinical signs appear among genders is not significant $p<0.05$. It is 44.5 months in male ferrets and 41.6 months in female ferrets. There is an average correlation $r=0.50$ between the age of male castration and appearance of clinical signs and a high correlation $r=0.82$ in the female ferret group.

\section{Occurrence of clinical symptoms in ferrets included in the research}

Table 1

\begin{tabular}{|l|c|c|c|c|}
\hline \multirow{2}{*}{ Clinical symptom } & \multicolumn{2}{c|}{ Male } & \multicolumn{2}{c|}{ Female } \\
\cline { 2 - 5 } & $\mathrm{n}$ & $\%$ & $\mathrm{n}$ & \multicolumn{1}{c|}{$\%$} \\
\hline Alopecia & 22 & 100 & 20 & 80 \\
\hline $\begin{array}{l}\text { Signs of oestrus (swollen vulva in females, mating } \\
\text { aggression in males) }\end{array}$ & 8 & 36 & 16 & 95 \\
\hline Pruritus & 16 & 73 & 19 & 85 \\
\hline Scaling and fragility of skin & 15 & 68 & 17 & 65 \\
\hline Lethargy & 13 & 59 & 13 & 20 \\
\hline Poliuria, polidipsia & 10 & 55 & 4 & 15 \\
\hline Abdominal enlargement & 7 & 32 & 3 & 55 \\
\hline Weight loss & 11 & 50 & 11 & 5 \\
\hline
\end{tabular}


Estradiol, androstenedione and $17 \alpha-\mathrm{OH}$ progesterone levels in female and male ferrets

Table 2

\begin{tabular}{|c|c|c|c|c|c|c|}
\hline \multirow[b]{2}{*}{ Nr. } & \multicolumn{3}{|c|}{ Male } & \multicolumn{3}{|c|}{ Female } \\
\hline & $\begin{array}{c}\begin{array}{c}\text { Estradiol } \\
(\mathrm{pmol} \mathrm{L}\end{array} \\
103.2-180)\end{array}$ & $\begin{array}{l}\text { Androstenedione } \\
\left(\mathrm{nmol} \mathrm{L} \mathrm{L}^{-1} 0.1-15\right)\end{array}$ & $\begin{array}{c}17 \alpha-\mathrm{OH} \\
\text { progesterone } \\
(0.1-0.8)\end{array}$ & $\begin{array}{l}\text { Estradiol (pmol } \\
\left.\mathrm{L}^{-1} 103.2-180\right)\end{array}$ & $\begin{array}{l}\text { Androstenedione } \\
(\mathrm{nmol} \mathrm{L}-10.1-15)\end{array}$ & $\begin{array}{c}17 \alpha-\mathrm{OH} \\
\text { progesterone } \\
(0.1-0.8)\end{array}$ \\
\hline 1 & 73.42 & $17.16^{*}$ & $0.93 *$ & $286.71 *$ & 10.50 & 0.05 \\
\hline 2 & $279.23^{*}$ & 4.82 & $4.14^{*}$ & 175.11* & 59.44* & 0.13 \\
\hline 3 & $205.89 *$ & 1.68 & 0.16 & 90.67 & $133.92 *$ & $0.27 *$ \\
\hline 4 & 81.49 & 10.50 & $2.61 *$ & 30.60 & 79.79* & $0.03 *$ \\
\hline 5 & 111.23 & $59.44 *$ & $3.60 *$ & 154.56 & $59.44 *$ & $0.77 *$ \\
\hline 6 & 114.90 & $25.70^{*}$ & $1.34 *$ & $218.06^{*}$ & 10.50 & 0.03 \\
\hline 7 & 122.98 & $20.48^{*}$ & 0.16 & 85.53 & $72.73 *$ & 0.03 \\
\hline 8 & 108.29 & 14.68 & $1.21 *$ & 40.01 & 10.48 & $0.47 *$ \\
\hline 9 & 200.44* & 10.49 & 0.10 & 45.50 & $16.40^{*}$ & $0.30^{*}$ \\
\hline 10 & $370.78^{*}$ & 0.30 & $1.30^{*}$ & $253.56^{*}$ & 14.69 & $0.25 *$ \\
\hline 11 & 106.83 & 13.64 & $1.05^{*}$ & 56.32 & $16.28 *$ & 0.08 \\
\hline 12 & 105.74 & $94.41 *$ & $0.84 *$ & 32.58 & 11.22 & $0.82 *$ \\
\hline 13 & $237.15^{*}$ & 10.48 & 0.10 & 106.87 & $71.45^{*}$ & 0.06 \\
\hline 14 & 36.70 & $20.34 *$ & 0.22 & $302.65^{*}$ & $23.76^{*}$ & 0.14 \\
\hline 15 & 62.04 & $17.49^{*}$ & 0.26 & 103.56 & $63.42 *$ & $0.20 *$ \\
\hline 16 & 93.24 & $32.01 *$ & 0.12 & 108.96 & $17.05^{*}$ & 0.03 \\
\hline 17 & 82.26 & $21.13^{*}$ & 0.20 & 193.62* & 13.47 & 0.03 \\
\hline 18 & $258.27 *$ & $17.92 *$ & 0.10 & 64.73 & $71.68^{*}$ & 0.03 \\
\hline 19 & $221.36^{*}$ & 12.70 & $0.84^{*}$ & 113.12 & $17.06^{*}$ & $0.20 *$ \\
\hline 20 & $300.23 *$ & $20.97^{*}$ & 0.45 & 195.44* & 11.86 & 0.03 \\
\hline 21 & 202.24* & 10.48 & $0.96^{*}$ & - & - & - \\
\hline 22 & $261.72 *$ & $78.43^{*}$ & 0.10 & - & - & - \\
\hline
\end{tabular}

* - hormonal level is increased.

At the evaluation of clinical symptoms, the most significant sign was symmetrical alopecia observed in all ferrets in various degrees included in this research (Tab. 1).

By our ranking system, most of ferrets had stage 3 $(n=19)$ and stage $2(n=17)$ alopecia, meaning they had permanent symmetrical alopecia on tail, back, extremities and chest. It is significant $p=0.05$, in male ferrets alopecia was more severe than in female. Third stage alopecia was observed in $55 \%$ of male ferrets whereas it was only $25 \%$ in the female group.

Signs of estrus - swollen vulva in female and mating aggression in male ferrets were observed in 24 animals. Abdominal enlargement was observed in 10 animals. Polyuria and polydipsia were observed in 14 animals. Pruritus was observed in 36 animals. Lethargy was observed in 26 animals. Scaling and fragility of skin was observed in 32 animals. Decreased weight was observed in 22 ferrets.
Out of 8 clinical symptoms listed in examination form, animals had min. 2 max. 7 of the mentioned. One male ferret had 2 clinical signs, other animals, male and female combined, had more. Two animals ( $\mathrm{n}=1$ female, $\mathrm{n}=1$ male) had 7 symptoms. Four animals ( $\mathrm{n}=2$ female, $\mathrm{n}=2$ male) had 3 symptoms. Nine animals ( $n=2$ female, $n=7$ male) had 4 symptoms. Sixteen animals $(n=10$ female, $n=6$ male) had 5 symptoms resulting in majority of animals included in this research. Ten animals $(n=5$ female, $\mathrm{n}=5$ male) had 6 symptoms. Thirty five animals $-83.3 \%(n=17$ female, $n=18$ male $)$ - had 4 to 6 clinical symptoms.

Sex steroid levels were compared with Adrenal panel. Results indicated that all ferrets had one or two elevated hormone levels (Tab. 2).

In the female group, 9 animals had increased one hormone and 11 had increased two hormones $(p=0.05)$. Androstenedione was elevated in 13 cases. 
In the male group, one hormone was increased in 8 cases and two hormones were elevated in 14 cases. Androstenedione was increased in 12 cases in the male group. Also in male group in 11 cases the level of $17 \alpha-\mathrm{OH}$ progesterone was increased. In our research, there was no case when all three sex steroids would be increased.

There was no correlation found between the clinical symptoms and hormone mesurements.

There is high possibility of estrogen induced bone marrow suppression if the female remains intact and is not fertilized. If jill is not brought out of the estrus, it may result in nongenerative anemia and death (Chen et al., 2014).

High prevalence $(r=0.82)$ in female group related to age at the castration and onset of clinical signs may be referred to the education of pet owners. Majority of jills in Latvia were neutered, before there was enough information about subcutaneous implants containing desloreline acetate which is manufactured for heat cycle regulation in various animal species. Implant also prevents the development of adrenal disease in ferrets. In Latvia, neutering is still more popular than desloreline acetate implants due to the price. For example, in England most of the ferrets are intact and prevalence of adrenal disease is low (Schoemeker et al., 2002).

The most often mentioned clinical symptom is alopecia. In our research it was observed in all animals. Ranking of alopecia for ferret adrenal disease has not been reported in research papers. It is mentioned that over years it gets more severe, eventually becoming persistent (Carpenter et al., 2012). It would be useful to rank the severity of alopecia when the ferret is for the first time brought for examination and further on as well.

Pruritus ( $\mathrm{n}=36$ animals), scaling and fragility of skin $(\mathrm{n}=32)$, lethargy $(\mathrm{n}=26)$, signs of estrus $(n=24)$, weight loss $(n=22)$ were observed in more than half of the animals forming majority of clinical symptoms. Signs of estrus (swollen vulva in female and mating aggression in male ferret) is mentioned as one of the most common clinical symptoms in ferrets with hyperadrenocorticism (Rosenthal et al., 1993). In our research, there are some symptoms that appear more often (pruritus, fragility of skin, lethargy).
Polyuria and polydipsia $(\mathrm{n}=16)$, abdominal enlargement $(n=10)$ were also observed. Various clinical symptoms may refer to other underlying conditions in these animals.

It is mentioned that in one animal numerous clinical symptoms may be noticed (Keeble et al., 2009).

In 16 animals $(\mathrm{n}=10$ female, $\mathrm{n}=6$ male) 5 symptoms were observed and only in 1 male ferret 2 symptoms were present.

Androstenedione is mentioned as the most sensitive hormone for the diagnosis of hyperadrenocorticism (Meredith \& Redrobe, 2002). There are research papers where only the level of androstenedione is detected (de Jong et al., 2014). In our research it was elevated in 25 cases out of 42 , which indicates that it is significant to detect other hormones as well.

\section{Conclusions}

1. Ferret clinical examination and sex steroid measurements are essential in the diagnosis of hyperadrenocorticism in domestic ferrets.

2. In our research, the female ferrets tend to develop adrenal disease earlier than male ferrets due to neutering at a young age.

3. Symmetrical alopecia, pruritus, scaling and fragility of skin, lethargy and signs of estrus are the most frequent clinical symptoms observed in our research.

4. Ranking of alopecia allows to evaluate the severity of it every time the ferret is brought for examination.

5. One animal had two clinical signs, two animals had seven clinical signs. The majority of ferrets had five $(\mathrm{n}=16)$ or $\operatorname{six}(\mathrm{n}=10)$ clinical symptoms of hyperadrenocorticism.

6. Level of androstenedione must be measured together with other sex steroids.

\section{Conflict of interest statement}

All ferrets were selected in various veterinary clinics. Owners and other veterinarians played no role in the study design nor in the collection, analysis and interpretation of data, nor in the decision to submit the manuscript for publication. None of the authors has any financial or personal relationships that could inappropriately influence or bias the content of the paper.

\section{References}

1. Banks, R.E., Doss, S.D., Sharp, J.M., \& Vanderford, D.A. (2010). Adrenal Disease. In: Exotic Small Mammal Care and Husbandry. Germany, Berlin: John Wiley \& Sons.

2. Beuschlein, F., Galac, S., \& Wilson, D.B. (2012). Animal models of adrenocortical tumorigenesis. Molecular and Cellular Endocrinology. 351(1), 78 - 86. DOI: 10.1016/j.mce.2011.09.045.

3. Bielinska, M., Kiiveri, S., Parviainen, H., Mannisto, S., Heikinheimo, M., \& Wilson, D.B. (2006). Gonadectomy-induced Adrenocortical Neoplasia in the domestic ferret (Mustela putorius furo) and laboratory mouse. Veterinary Pathology. 43(2), 97 - 117. DOI: 10.1354/vp.43-2-97. 
4. Bielinska, M., Parviainen, H., Kiiver,i S., Heikinheimo, M., \& Wilson, D.B. (2009). Origin and Molecular Pathology of Adrenocortical Neoplasms. Veterinary Pathology. 46(2), 194 - 210. DOI: 10.1354/vp.46-2194.

5. Carpenter, J.W., \& Quesenberry, K.E. (2012). Ferrets, Rabbits and Rodents Clinical Medicine and Surgery. 3rd ed. USA, St. Louis, Missouri: Saunders Elsevier.

6. Chen, S., Michels, D., \& Culpepper, E. (2014). Nonsurgical Management of Hyperadrenocorticism in Ferrets. Veterinary Clinics of North America: Exotic Animal Practice. 17(1), 35 - 49. DOI: 10.1016/j. cvex.2013.09.001.

7. Coleman, G.D., Chavez, M.A., \& Williams, B.H. (1998). Cystic prostatic disease associated with adrenocortical lesions in the ferret (Mustela putorius furo) Veterinary Pathology. 35, 547 - 549. DOI: $10.1177 / 030098589803500612$.

8. Fox, G., James. (1988). Physiology of the ferret. In: Biology and Diseases of Ferret. 2nd edition. USA, Philadelphia: Lea \& Febiger.

9. Hnilica, K.A. (2010). Small Animal dermatology: A Colour Atlas and Therapeutic Guide. USA, Missouri, St. Louis: Elsevier Health Sciences, Saunders Elsevier.

10. de Jong, M.K., ten Asbroek, E.E.M., Sleiderink, A.J., Conley, A.J., Mol, J.A., \& Schoemeker, N.J. (2014). Gonadectomy-related adrenocortical tumors in ferrets demonstrate increased expression of androgen and estrogen synthesizing enzymes together with high inhibin expression. Domestic Animal Endocrinology. 48, 42 - 47. DOI: 10.1016/j.domaniend.2014.02.002.

11. Keeble, E., \& Meredith, A. (2009). BSAVA Manual of Rodents and Ferrets. England, United Kingdom, England, Gloucester: British Small Animal Veterinary Association.

12. Meredith, A., \& Redrobe, S. (2002). BSAVA Manual of Exotic Pets. 4th edition. England, United Kingdom, England, Gloucester: British Small Animal Veterinary Association.

13. Mitchell, M.A., \& Tully, T.N. (2009). Manual of Exotic Pet Practice. USA, Philadelphia: Saunders.

14. Rosenthal, K.L., Peterson, M.E., Quesenberry, K.E., Hillyer, E.V., Beeber, N.L., Moroff, S.D., \& Lothrop, C.D. jr. (1993). Hyperadrenocorticism associated with adrenocortical tumor or nodular hyperplasia of the adrenal gland in ferrets: 50 cases (1987 - 1991). Journal of the American Veterinary Medical Association. 203(2), 271 - 275. PMID: 8407489.

15. Rosenthal, K.L., \& Peterson, M.E. (1996). Evaluation of plasma androgen and estrogen concentrations in ferrets with hyperadrenocorticism. Journal of the American Veterinary Medical Association. 209(6), 97 102. PMID: 8800255 .

16. Rosenthal, K.L., \& Peterson, M.E. (2000). Kirk's current veterinary therapy XIII, small animal practice. Philadelphia: Saunders.

17. Schillebeeck, M., Pihlajoki, M., Gretzinger, E., Yang, W., Thol, F., Hiller, T., \& Wilson, D.B. (2015). Novel markers of gonadectomy-induced adrenocortical neoplasia in the mouse and ferret. Molecular and Cellular Endocrinology. 399, 122 - 130. DOI: 10.1016/j.mce.2014.09.029.

18. Shoemaker, N.J., Schuurmans, M., Moorman, H., \& Lumeij, J.T. (2000). Correlation between age at neutering and age at onset of hyperadrenocorticism in ferrets. Journal of the American Veterinary Medical Association. 216(2), 195 - 197. DOI: 10.2460/javma.2000.216.195.

19. Schoemaker, N.J., Treeds, K.J., Mol, J.A., Lumeij, J.T., Thijssen, J.H., \& Rijnberk, A. (2002). The role of luteinizing hormone in the pathogenesis of hyperadrenocorticism in neutered ferrets. Molecular and Cellular Endocrinology 197(1-2), 117 - 125. DOI: 10.1016/S0303-7207(02)00285-X. 